\title{
Greimas e o desenvolvimento gerativo da imanência semiótica
}

\author{
Francesco Marsciani' \\ https://orcid.org/0000-0002-2987-0697
}

I - Centro Universitario Bolognese di Etnosemiotica Bologna, Itália

Resumo: Neste artigo, a tentativa é de mostrar como e a que ponto pode-se considerar a proposição teórica central de Greimas, ou seja, a articulação gerativa do conjunto das condições da significação como uma resposta do mais alto nível às questões deixadas em suspense pelas duas tradições maiores que refletiram sobre as linguagens e sobre o sentido no curso do último século, de um lado, a fenomenologia e, de outro lado, a glossemática hjelmsleviana.

Palavas-chave: efeitos de sentido; forma; glossemática; imagem; fenomenologia; semiótica gerativa; substância.

Abstract: Greimas and the Generative Development of Semiotic Immanence - In this essay, the aim is to show how and how much it is possible to consider the most important theoretical proposition of A.J. Greimas, i.e. the generative articulation of the totality of signification conditions, as the most adequate answer to the questions left unresolved by the two most important traditions in the study of languages and sense all along the last century: the phenomenology on one side and the hjelmslevian glossematics on the other.

Keywords : Sense effect; form; glossematics; image; phenomenology; generative semiotics; substance.

Pretendo discorrer com a sinceridade um pouco ingênua do aluno que fui e com a postura aberta do discípulo: a leitura que sempre trouxe comigo no aprendizado e nas reflexões sobre a teoria de Greimas, além dos frutos e referências que tomei para o meu trabalho, foi sempre centrada e orientada, como creio que tenha sido o caso de muitos jovens estudantes de semiótica daquela época, em torno de um texto breve, simples e inaugural, extraordinariamente denso, porém, límpido e claro, como uma intuição feliz e decisiva: trata-se do artigo usado como introdução ao volume Du sens (GREIMAS, 1970), páginas que também carregam o título "Du sens", e que se abrem com as famosas palavras "é extremamente difícil falar do sentido e dizer algo sensato a seu respeito". Li como estudante 
e depois como colaborador (se posso dignar-me a assim me considerar com relação a um período infelizmente curto e final da vida ativa de Greimas) toda a sua obra - voltando às investigações do linguista e lexicólogo pré-semiótico e seguindo-o até os últimos estudos relacionados à reavaliação da dimensão sensível da significação - iluminado em certo sentido por esse farol, à luz desse ensaio, apoiado pelo que parecia ter compreendido naquelas páginas, mesmo nos momentos em que a comparação com o pensamento do mestre parecia mais difícil, o desdobramento de suas ideias menos linear, mais aventureiro e, às vezes, perigosamente inclinado para uma dimensão de impressionante radicalismo teórico.

"É extremamente difícil falar do sentido e dizer algo sensato a seu respeito": percebia isso e parecia-me completamente de acordo, porque toda a filosofia e a semiótica de onde eu vinha me indicavam justamente essa dificuldade como central e dominante, mas o que me fascinava era o curto-circuito que se deixava perceber e saborear sobre o termo "sentido", como se Greimas tivesse decidido desvelar a dimensão paradoxal de um terreno sobre o qual o pensamento e a epistemologia do século XX tinham explorado todo o tipo de hipóteses e refutações, de construções conceituais e desconstruções, de fundamentações e inversões. O sentido como um terreno paradoxal e ao mesmo tempo singular, o único, necessário e feliz em sua produtividade para o exercício de uma razão semiótica finalmente liberada, autoconsciente e responsável, dotada de um poder teórico bem fundamentado e projetada sobre um compromisso disciplinar a se realizar, sobre uma vocação científica e descritiva a ser proposta para o conjunto das ciências sociais, sobre um modelo renovado de racionalidade a ser construído.

"Falar do sentido e dizer algo sensato a seu respeito"... nas dobras dessa formulação se entrevê uma dissociação entre um sujeito e um objeto da enunciação totalmente idênticos, na aparência, e ao mesmo tempo separados e distintos por esta que devia aparecer e, então, ser tratada como uma função essencial, imprescindível, possibilitada por uma distância constitutiva, a que Greimas chamou precisamente nesse texto de "função metalinguística". O sentido é simples e imediatamente sentido, não mais que sentido; é dado, nele o discurso, que não é nada mais do que o sentido articulado, está sempre imerso, mas esse sentido, que é único, é ao mesmo tempo e distintamente sentido que diz o sentido e sentido dito, falado, expresso, pelo sentido que diz. As proposições que Greimas desenvolveu em Du sens tiveram o efeito de colocar em circulação os polos de uma relação íntima e fundamental entre as condições da significação, e isso já na prefiguração de uma teoria que estava tomando forma e que, a partir desse momento, ocuparia todo o espaço que lhe caberia, de acordo com a organização de níveis que conhecemos como a forma gerativa da imanência semiótica. O sentido não é nada mais que o sentido, em qualquer circunstância e ocorrência, no entanto, nunca é o mesmo sentido que se realiza, uma vez que não se pode compreendê-lo de outra maneira senão através de suas transformações, as paráfrases que a discursividade produz, as transposições que cada abordagem, cada retomada, cada olhar, renovam e alimentam. 
Por meio da focalização do lugar próprio do paradoxo, Greimas tornava explícita e evidente uma abordagem de muitas experiências convergentes que alcançaram um ponto final em seu percurso. Tal ponto tinha um nome e ele não fez mais que retomá-lo e torná-lo o título de um programa, uma vez que, para todo um conjunto de tradições do século XX, esse ponto de chegada não era nada mais que o sentido, o sentido como problema, como descoberta e como dimensão. Nesse limiar, que foi de fato conclusivo, juntava-se, como em um encontro coletivo ou uma reunião, a fenomenologia, a filosofia da linguagem, o formalismo lógico e estrutural e a própria linguística, que Greimas cultivava em particular e que era um especialista. As ciências humanas, por sua vez, estavam se reconhecendo como disciplina do sentido, implicadas com a significação em seu estatuto constituinte. O volume Du Sens (GREIMAS, 1970) e a sua introdução expõem como em um manifesto o objeto de uma pesquisa a ser promovida, quase o lugar autêntico de uma revolução a ser empreendida no campo do conhecimento.

Assim, a semiótica se via posicionada no cruzamento de tendências diferentes entre si, mas não estranhas, e o programa de trabalho encontrava no artigo de que estamos falando tanto uma justificativa explícita quanto uma indicação do caminho a seguir. São mencionados os limites dos projetos logicistas, voltados para a construção de línguas formais, sob a ilusão de que línguas inteiramente separadas de suas significações não possam jamais ser construídas, como se o sentido pudesse ser extraído das expressões simbólicas da lógica formal; os limites opostos dos procedimentos descritivos em relação direta com o sentido dado, de acordo com uma versão fenomenológica do discurso crítico e uma versão literária das reformulações que envolvem a subjetividade; os atalhos fáceis e falsos de uma conceituação apriorística das teorias e modelos; sobretudo, se enfatizarmos o fato de que o espaço para uma teorização e uma análise da significação não pode ser pensado fora do sentido, nem acima, nem abaixo, nem em outro lugar, mas somente nas dobras da sua manifestação, nessa relação entre o dizer e o dito que sustenta a função metalinguística generalizada (a metalinguagem que é a nossa prática discursiva cotidiana) e que leva em consideração a estrutura fundamental da produção da significação, nessa relação constitutiva representada pela pressuposição recíproca entre a dimensão sistêmica e a dimensão processual.

São duas as principais linhas de desenvolvimento às quais a semiótica, que vai se moldando nos passos de Semântica Estrutural, pretende responder: uma ligada à tradição fenomenológica, husserliana e merleau-pontyana, e a outra, à linguística estrutural, saussuriana e hjelmsleviana, cabendo, contudo, elaborar uma posição adequada para essa convergência, uma dimensão já experimentada e praticada, à sua maneira, é verdade, pela antropologia social de Lévi-Strauss. Em ambos os casos, considerando a fenomenologia, de um lado, e a linguística estrutural, de outro, será necessário lidar com as tendências formalizantes e buscar dar à instância formal, à noção mesma de "forma", o lugar e o papel justos na teoria. No ensaio Du sens, Greimas (1970) parece querer trabalhar, 
acima de tudo, com a noção de forma, tentando restituir-lhe uma versão propriamente semiótica, isto é, adequada ao paradoxo de um sentido que pretende dizer algo de sensato sobre o sentido.

A forma semiótica não é senão o sentido transformado, o lugar de refazer o sentido, linguagem que expõe as condições da linguagem, que se desenrola expressando as topologias necessárias para justificar os efeitos da significação. É o resultado das transformações, uma vez que nos coloca em uma dimensão subjacente, a partir da qual podemos avaliar a transformação como uma dinâmica de mediação, como um "entre", como uma verdadeira metamorfose que ocorre e se manifesta na superfície onde se localiza e se colhe o dado empírico. Nega-se, portanto, uma ideia de forma separada do devir das transformações do sentido, uma forma construída a priori baseada em suposições extrassemióticas, em estruturas lógicas ou axiomas apoiados em alguma metafísica do logos, aplicável ao objeto sentido como parte exterior. Não creio que até o momento tenha alcançado toda a sua importância e consequências uma escolha tão radicalmente imanentista, tão estrutural, no sentido próprio, tão radical.

A semiótica que estava surgindo e, principalmente, que estava assumindo a forma gerativa que Greimas pretendia Ihe dar, encontrava-se ocupando um lugar de convergência, conforme dissemos, sobretudo entre dois desfechos, que manifestavam as abordagens finais de duas perspectivas, conduzidas ao limite extremo, levadas à fronteira de seu campo de atuação:

1) A fenomenologia de Husserl tinha encontrado a inconsistência da dimensão individual, egoica, da consciência no momento de maior aproximação das estruturas transcendentais da doação de sentido, naquela passagem, no final da Quinta Meditação Cartesiana e, novamente, em A Crise das ciências europeias, em que descobre que a subjetividade transcendental não pode existir senão sob a forma de uma intersubjetividade constitutiva. A decorrência mais imediata é a perda da validade da autointuição como modalidade profunda da investigação reflexiva. Não é mais concebível trabalhar na análise das formas próprias da consciência, mas a "ciência rigorosa" da possibilidade dos fenômenos não pode prescindir de uma reconstrução sistemática das relações entre os polos da constituição, entre os pontos de vista, posições e, como dirá o próprio Husserl, os sistemas de incompossibilidade. Podemos dizer que esta é a maneira pela qual o Sentido se apresenta no final do percurso da fenomenologia (basta pensar em Merleau-Ponty de Signos).

2) A glossemática hjelmsleviana tinha encontrado uma impossibilidade de fato, a de manter o voto de simetria entre os planos fundamentais para toda a perspectiva formal sobre a qual o projeto havia sido pensado, e isso porque a análise do plano do conteúdo das línguas naturais não se presta a resultados exaustivos no que diz respeito aos elementos últimos, as figuras mínimas: não há arquivos 
em número limitado de figuras do conteúdo. Além da tentativa de Hjelmslev, legítima em si, de decidir cada vez proceder "como se" uma figura do conteúdo não tivesse um correspondente no plano da expressão, em suma, não constituísse, por sua vez, imediatamente um signo, é evidente que tal operação só é possível delimitando aqueles que serão chamados "universos de sentido específicos" ou "microuniversos de sentido". A relação semiótica entre o plano de expressão e o plano de conteúdo apresenta-se, assim, como uma produção constante de pressuposição recíproca, como uma correlação instável que, de tempos em tempos, o Sentido realiza nas substâncias que informa, graças ao sistema de relações que cada processo textual lança como uma rede nas formações sígnicas. Mas isto é o contrário da relação de denotação e toda a análise semiótica (e, do ponto de vista semiótico, a língua natural não é exceção,) se vê inevitavelmente projetada sobre a forma como articulação possível das determinações de Sentido, ou melhor, como produção das possíveis articulações que põem o Sentido em condições de significar. Podemos ainda dizer que esta é a forma pela qual o Sentido irrompe na linguística estrutural em sua versão mais formalizada.

A semiótica de Greimas é a resposta para tudo isso, uma vez que se coloca em relação direta e explícita com ambas as tradições, mas, ao mesmo tempo, marca sua distância, assumindo as dificuldades de cada uma como oportunidade para um avanço fundamental: é o Sentido que diz o sentido, que reflete sobre o sentido, que coloca o sentido na forma e reconstrói as condições formais das possibilidades.

Tal escolha tem um aporte epistemológico considerável: trata-se de transpor definitivamente os limites fundacionalistas que inevitavelmente assumem um ou outro dos dois pontos de vista opostos para dar uma base ao nosso saber, isto é, 1) o de um fundamento empírico das validades das teorias e das afirmações científicas, medindo a verdade das afirmações sobre a correspondência representacional entre a linguagem e o mundo da experiência, ou 2) o da garantia da validade das proposições científicas sobre a bondade e correção dedutivista das fórmulas metalinguísticas, baseadas essencialmente nas teorias apriorísticas (lógico-dedutivas) do bom raciocínio. O Sentido não corresponde nem a uma nem a outra dessas condições. A semiótica que finalmente vai se delineando já não coloca em jogo o plano do discurso verdadeiro, da "explicação científica" no sentido tradicional, já não pretende explicar os fenômenos, nem a sua produção de acordo com determinadas leis, nem a natureza da sua existência. A semiótica que Greimas vislumbra na época de Du Sens (GREIMAS, 1970) é uma prática "de vocação científica" de implantação das condições de possibilidade do valor dos fenômenos, de seu ter sentido, não de seu ser o que são ou da sua ocorrência, mas do seu significar. Ou se compreende esta passagem, alcançada com base nos resultados da fenomenologia madura (o último Husserl e o segundo Merleau-Ponty) e da linguística estrutural, em sua forma mais avançada 
(a glossemática de Hjelmslev), ou não se percebe o extraordinário valor inovador de uma tomada de posição que é um programa de pesquisa completo, que é uma verdadeira inversão de perspectiva, sem campo externo de onde se observar ou tomar a palavra, sem garantias intuicionistas, sem provas para confiar, mas totalmente elaborado dentro da única condição aparentemente insuprimível, a única dimensão sem Deus acima e a natureza abaixo, a única ciência que pode ser concebida como prática do conhecimento, como devir histórico e ao mesmo tempo transcendental de toda proposição que tome o universo de discurso como objeto: a dimensão da transformação, do Sentido como transformação do sentido dado.

No fundo, tal escolha não tinha alternativas. Tratava-se da única tentativa séria não somente de dar uma resposta aos impasses de uma ciência ao mesmo tempo formalizante e objetivista, mas de tentar criar um espaço de viabilidade para a sua superação, para produzir um avanço. Como fazer ciência do sentido (dizer algo sensato a seu respeito...) sem adotar as explicações dos fenômenos da experiência assumidos como objetos "dados", por um lado, e sem fazer deduções materiais, construções arbitrárias de fórmulas descritivas, dissociadas do discurso que deveriam representar, por outro? Nessa lacuna, resolvia-se o próprio fato de uma estagnação e, com efeito, começavam a tornar claramente visíveis no horizonte os refluxos de várias naturezas, as renúncias em sua maioria, ou mesmo os retornos às exigências de uma ciência protocolar, concentrada inteiramente entre a aceitação de um plano objetal natural (e por isso, de fato, renaturalizado) e de uma produção logicista de modelos em grande escala, de tipologias, de "teorias" dos funcionamentos causais.

Fazer ciência do sentido de uma maneira nova, digamos adequada à descoberta da dimensão do sentido como terreno paradoxal e reflexão de produção significante, pedia a abertura de um campo de criação de possibilidades, onde se pudesse exercer uma verdadeira suspensão de julgamento (inspiração fenomenológica) em relação à objetividade dos signos e, ao mesmo tempo, desenvolver uma cadeia de articulações, cada vez mais finas e detalhadas, de espaços qualitativos, de diferenciação (inspiração estrutural).

Acredito que era essa a intuição essencial que guiava Greimas em seu trabalho de construção do Percurso Gerativo e que possa valer à pena ainda hoje fazer uma leitura que leve em conta essa inspiração, salvaguardando seu enorme valor científico, sua enorme habilidade de controle sobre o fazer descritivo e a grande capacidade de formalização de uma racionalidade viva, imersa em sua natureza mais autêntica, ou seja, uma racionalidade em harmonia com o seu produzir-se como significação.

Uma leitura como essa tem algumas implicações:

1. O Percurso Gerativo não é o percurso de geração do conteúdo ou de geração da expressão; é o percurso de geração da significação. O conteúdo e a expressão não são tais enquanto não se concretizam em substâncias da manifestação, mas esse é o nível empírico de produção dos signos, no qual uma semiótica de 
inspiração hjelmsleviana deve necessariamente se distanciar. Pode-se dizer que o percurso gerativo em todos os seus níveis articula figuras, elementos subsígnicos que para a semiótica são equivalentes às condições subjacentes em relação às substâncias da manifestação.

2. A forma que o percurso gerativo articula não é nada mais que substância. Não há formas que possam ser encontradas em outro lugar em relação à produção viva do sentido articulado, em relação ao "sentido que fala do sentido", mas a distância metalinguística, enfatizada por Greimas, cria efetivamente as condições para que as substâncias-objeto e o discurso que lhes referem não coincidam, mas entrem em função recíproca, de modo que podemos considerar a função metalinguística como a produção dos níveis formais necessários para explicar como as substâncias-objeto significam. Dentro das transformações do sentido, entre uma substância e outra, entre um efeito de sentido e outro, a forma aparece como uma função de permanência, de comparabilidade, como um depósito. A forma não é nada mais que uma substância que serve como forma para a resolução da significação de outra substância.

3. Os níveis do Percurso Gerativo não preveem atalhos. Não há saídas privilegiadas para economizar nas articulações ou passagens que conecte planos distantes ao longo da escala de profundidade. Tal hipótese simplesmente não tem sentido algum: os níveis do Percurso Gerativo constituem em conjunto a reconstrução teórica das condições de possibilidade da significação e, como tais, estão sempre presentes como condições. O fato de que uma produção textual qualquer possa ativar ou se beneficiar de modo particular de algumas das articulações possíveis e, assim, não explorar todas as formas que o Percurso prevê, não quer, de modo algum dizer, que estas formas não estejam, a qualquer momento, disponíveis para a significação. O Percurso Gerativo, como tal, não descreve esta ou aquela manifestação textual, não tem relação com o recorte empírico dos objetos-signo em que pode ser projetado, não tem razão alguma para "adequar-se" às substâncias que a função de significação coloca na forma. Esse é o espaço topológico para o deslocamento funcional das linguagens que falam das linguagens, todas as linguagens em todos os momentos.

4. O Percurso Gerativo não gera textos, manifestações da significação ou signos, não é, em especial, a representação, o modelo, as etapas de produção da textualidade empírica. Não se produzem textos através das passagens, conversões e investimentos sucessivos que ele teoriza e reconstrói. O Percurso Gerativo, ao invés disso, gera possíveis espaços qualitativos formais que não são mais do que as condições de significação de um elemento de manifestação qualquer, 
pressuposta a sua significação. Deste ponto de vista, o Percurso Gerativo, por mais que se queira ou se deva percorrer, prevê duas direções distintas: de cima para baixo (do nível superficial ao nível mais profundo) quando se analisa objetos de sentido, quando se busca a justificativa de um determinado efeito de sentido, na sua manifestação; ou de baixo para cima, na direção oposta, seguindo as linhas de desenvolvimento das possibilidades topológicas e combinatórias que ele fornece por meio da multiplicação das conexões formais.

Se admitirmos a leitura do Percurso Gerativo, proposto por Greimas, segundo essas linhas, assegurando esses limites interpretativos, então, uma primeira consequência é que obtemos uma grande vantagem em manter o seu espaço o mais aberto possível, ou seja, em garantir a máxima abrangência à dimensão da qual é a representação. Não há benefício algum na redução de seu alcance. Se o Percurso Gerativo articula formas, condição da significação das substâncias, então, quanto mais articulações pudermos produzir, mais possibilidades teremos para explicar a significação das inúmeras manifestações textuais que encontraremos na vida discursiva concreta. Pode-se temer que a proliferação teórica das articulações formais possa sair do controle, multiplicar os níveis e assim correr o risco de seguir o múltiplo empírico, mas esta é uma preocupação injustificada, seja porque estamos falando de metalinguagem e essa função enquanto tal não se dispersa (a metalinguagem não é uma produção livre de formas arbitrárias, mas é metalinguagem de uma linguagem-objeto em uma relação destinada a ser a dois), seja porque o Percurso Gerativo é uma hierarquia de níveis em que a direção "abstrato-concreto" ou "profundo-superficial" desempenha uma função de controle extraordinária (a condição de diferenciação é "anterior" e não se pode prosseguir indefinidamente em direção ao mais elementar - como ensina a física quântica, a realidade é atomística - e, por outro lado, a condição empírica é definitiva, o limite superior do Percurso é intransponível, no sentido de que a dimensão da imanência não pode transbordar, de modo algum, na transcendência, além de sua fronteira.

O plano da manifestação não é o dos signos, nem, para ser preciso, o dos textos. O plano da manifestação é o dos efeitos de sentido. Os signos são abstrações teóricas, conceitos funcionais sem natureza ontológica empírica, e os textos não são dados, mas objetos de análises pressupostas e que lhes fornecem precisamente a qualidade de objetos possíveis, de um olhar científico. No plano da manifestação são produzidos, presentificados e encadeados os efeitos de sentido que, são, portanto, o primum, o ponto de partida, a face do mundo. Os efeitos de sentido deixam-se colher na singularidade dos fenômenos significantes, em seu sobrevir particular e específico. De fato, o sentido torna-se acessível por meio de seus efeitos, pelos quais se estabelecem suas transformações e que permitem que o sentido em si não seja senão a transformação do sentido dado, em uma cadeia de efeitos de sentido que é feita de instabilidade, de deslizamentos e traduções constantes, em um horizonte de investimentos de valores variáveis e multiformes (inerência, atenção, intenção, emoção, cognição, percepção ou concepção). 
Ora, uma teoria das transformações do sentido, na medida em que esses se realizam por meio de encadeamentos de efeitos de sentido, é uma teoria da experiência. Trata-se de uma teoria semiótica da experiência, na medida em que é uma teoria das possíveis valorizações do mundo vivido enquanto mundo da vida, espaço em que emergem os fenômenos, isto é, das valorizações das datidades. O mundo da vida (o Lebenswelt fenomenológico) reencontra, dentro de um destino semiótico possível, um modo de ser relido e reinterpretado como dimensão da significação. É um mundo sensível, carregado de valor, porque é o mundo em que os efeitos de sentido emergem, em que as coisas fazem sentido, as quais, por assim dizer, não são coisas, mas antes, fenômenos, um mundo investido, desde o início, pelas formas significantes que o articulam.

Como falar desse mundo, como falar dessa experiência, "como dizer algo sensato sobre ela"? O problema não é recente, uma vez que a semiótica se define a partir de um primeiro passo, que é um marco inicial: ela não tem como objeto as coisas, o mundo empírico, as substâncias da manifestação, mas as condições formais imanentes que explicam a significação como articulação. Ora, como acessar o mundo da vida, da experiência vivida, dos efeitos de sentido? Por meio de qual canal, qual abertura? Estou convencido de que Greimas, diante de um problema como esse, que ele conhecia tão bem, tinha intuído um caminho possível, e de que essa intuição foi herdada sobretudo por Da Imperfeição, seu texto final e limiar, que definiu fronteiras, desenvolvido inteiramente na imanência, mas aberto às variações da experiência vivida. Claro que para extrair dessa obra tal percepção é necessário lê-la como uma experiência de semantização em ato, como uma tentativa de praticar um ensaio da axiologização que Greimas acreditava ser a vocação mais profunda da disciplina à qual dedicou toda a sua vida.

Trata-se de jogar com os desvios dos efeitos de sentido, deixar-se levar pelo fluxo das transformações, explorar as possíveis direções que os encadeamentos podem assumir. Em outras palavras, deixar a forma emergir dentro das próprias transformações, colocar-se nas condições de apreciar o que exatamente permite que uma transformação ocorra como tal, ou seja, a permanência dos traços formais de conexão, das formas comuns entre o antecedente e o subsequente, entre um efeito de sentido e sua derivação. Trata-se de interpretar a forma sob as cadeias transformativas dos dados empíricos, de transpor cada efeito de sentido, graças aos encadeamentos que constrói na sua imagem. O que quero dizer com "imagem"? Refiro-me ao lado formal, sob o limite da imanência, do efeito da substância pela qual o sentido se manifesta, isto é, uma totalização estrutural de traços formais e de linhas de força, que permitem ao efeito do sentido, precisamente, fazer sentido, ser o que é, um fenômeno valorizado, interpretável, dirigido, intencionado. À imagem bastam dois efeitos de sentido conectados entre si e com esses poucos e escassos materiais à sua disposição, com esse simples encadeamento de substâncias eficazes, de "vividos", ela é capaz de produzir uma totalização, ou seja, constituição de mundo, 
determinação da qualidade do horizonte sistêmico, plano isotópico de pertinência e de referência. Desse modo, a imagem já é texto, constitui uma tessitura, entrelaçamento de relações estruturais disponível para a sua reelaboração como objeto analítico, já é, enquanto tal, um objeto semiótico.

No entanto, verifica-se também como a constituição de tal objeto não pode prescindir da operação de derivação controlada que a instância receptiva, o enunciatário do sentido enunciado do mundo, pode produzir e sustentar. A imagem não pode ser separada da observação dos efeitos de sentido em que as transformações do mundo da vida são articuladas. Em outros termos, não se pode fazer análise semiótica senão a partir da observação das transformações e das produções de imagens que elas determinam. Os textos, enquanto objetos de análise, não são dados, não são objetos que encontramos no mundo. Nesse, encontramos apenas efeitos de sentido. É a observação do modo como esses efeitos de sentido emergem e se encadeiam que produz o mínimo de estabilidade formal a que podemos atribuir a qualidade de texto, ou seja, de objeto adequado para a análise semiótica da significação.

A esta prática, "de vocação científica", de acordo com uma máxima que consideramos um dos maiores ensinamentos de A. J. Greimas - que, por sua vez, foi um dos poucos grandes pensadores do século passado - dedicamos, em nosso trabalho de pesquisa na Universidade de Bolonha, o exercício e o desenvolvimento do que denominamos etnossemiótica: uma prática de pesquisa, uma reflexão sobre as condições de produção do sentido, uma elaboração de um campo de estudo que tem como centro de suas preocupações a observação enquanto tal, ou seja, a observação enquanto constituinte do valor dos fenômenos. É somente por meio dessa constituição que os fenômenos, por meio do seu produzir-se em imagem, podem adquirir a qualidade de textos, ou seja, objetos adequados para uma análise semiótica consciente, sem a ingenuidade dos formalismos, adepta às experiências vividas, mas ao mesmo tempo capaz de manter firme a distância metalinguística, a "boa distância" da observação, a vocação científica.

Traduzido do italiano por Simone Bueno.

Francesco Marsciani integra o CUBE (Centro Universitario Bolognese di Etnosemiotica). Publicou os livros Introdução à etnossemiótica, Tracciati di etnosemiotica, Esercizi di semiótica generativa. Dalle parole alle cose, Paul Ricoeur e Algirdas J. Greimas. Tra semiotica ed ermeneutica.

francesco.marsciani@unibo.it 


\section{Referências}

GREIMAS, J. A. Du Sens: essais sémiotiques. Vol. 1. Paris: Éditions du Seuil, 1970.

MARSCIANI, F. Le goût et le Nouveau Monde. In: LANDOWSKI, E. (Ed.). Sémiotique gourmande. Nouveaux Actes Sémiotiques, 55-56, 1998.

Dei miracoli del sensibile. In: LANDOWSKI, E.; DORRA, R.; OLIVEIRA, A. C. de (Orgs.). Semiótica, estesis, estética. São Paulo-Puebla: EDUC-UAP, 1999.

. Introdução à etnossemiótica. Galáxia, 23, 2012.

Introdução à etnossemiótica". Tradução Silvia Alencar, revisão Ana Claudia de Oliveira e Marcelo Machado Martins. Documentos de Estudo do Centro de Pesquisas Sociossemióticas, n. 7, São Paulo: CPS, 2012.

. La città e la sua immagine. In: OLIVEIRA, A. C. de. As interações sensíveis. Ensaios de sociossemiótica. São Paulo: Estação das Letras e Cores, 2013.

Tracciati di etnosemiotica. Milano, FrancoAngeli, 2007. Tr. fr., Les arcanes du quotidien. Essais d'ethnosémiotique. Limoges: Pulim, 2017.

Texto recebido em 07/08/2019

e aprovado em 20/10/2019. 